\title{
Students' Humanistic Position Formation in the Educational Process
}

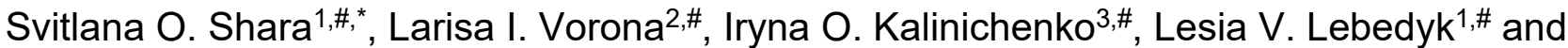 \\ Larisa M. Olifira ${ }^{4, \#}$
}

${ }^{1}$ Poltava University of Economics and Trade, Poltava, Ukraine

${ }^{2}$ Luhansk Taras Shevchenko National University, Starobilsk, Ukraine

${ }^{3}$ Poltava Regional Institute of Postgraduate Pedagogical Education named after N.V. Ostrogradsky, Poltava, Ukraine

${ }^{4}$ University of Management Education, Kyiv, Ukraine

\begin{abstract}
Objective: The student's humanistic position is not only the result of the teacher's personal influence but also a controlled process. As a result of the implementation of this process, the student receives an understanding of what should relate to the humanistic process and the humanistic function of society.

Background: The basis for the formation of humanism for all participants in the students' educational process is determined either by the teacher's position or by the installation in the pedagogical process. So, any impact on the part of the teacher can be perceived as an exceptional factor of influencing the student's personality, which can be perceived as a compulsory education requirement.

Method: Assessment of pedagogical effectiveness was carried out by means of an expert survey. Diagnostic and processing of empirical data was carried out according to the methodology for assessing the importance of each individual requirement for the proposed educational materials.

Results: The study examines the components that form the student's humanistic position on the basis of the traditional components of the formation of the pedagogical teaching strategy. The practical significance of the study is determined by the fact that it is possible to implement the concept of the formation of active skills in students during certain actions and the formation of other humanitarian positions.

Conclusion: The study shows that the level of formation of the students' humanistic position concerning all participants in the educational process depends on updating the educational process of training specialists based on the developed theoretical and methodological foundations.
\end{abstract}

Keywords: Humanism, position, training, students, university.

\section{INTRODUCTION}

The purpose of professional training in a higher educational institution is to satisfy the growing demand of society in highly qualified specialists who possess thorough theoretical knowledge and practical skills for their effective application in the process of forming a humanistic position (Weiner 1985), implementation of technologies; have leadership skills, high moral qualities, are competitive in the labour market, effectively interact in a professional, corporate and social environment, with social mobility and having a steady demand among employers (Aloni 2003b).

The educational professional training program at a higher educational institution aims at deep, comprehensive study of forms and processes, understanding of various ways of working and a variety of cultural influences (Kato 2014), allows you to master modern positions as a field of humanitarian and social knowledge and academic discipline, contributes to the development of essential skills of practical activities in the field of culture (Suransky 2017).

The concept of training is built on the basis of curricula consisting of several cycles of disciplines: humanitarian and socio-economic disciplines, disciplines of natural science (fundamental) training, general vocational training disciplines, professional and practical training disciplines, selective academic disciplines (Zilsel 2003). In this regard, the place of the humanistic position is to form a meta-subject significance for pedagogical influence.

At the modern stage of development, which is marked by substantial changes in all spheres of social life, the 
powerful progress of fundamental sciences, high-end technologies (Gregersen and Køppe 1989), the scale of scientific technologies, one of the most urgent tasks is the formation of a humanistic position as the foundation, the source of modern human activity (Aloni 2003c). Today, the humanistic position is considered as one of the main paths to activation and modernization of the activities of subjects of all sectors (Parkinson 1987). Some aspects of the content of the concept of "humanistic position" and the ways and means of its formation in future specialists with higher education were considered in the works of various authors (Aloni 2003a). According to some of them, foreign economists and representatives of related industries were the first to start studying the concept of a humanistic position (Kwak 2017). Later, the humanistic position became the subject of study by sociologists. (Bakker 2011).

Undoubtedly, for a thorough research of the humanistic position, the content of this concept should first be clearly understood (Fabian and Vierhaus 1979), because a clear interpretation of the concept of a humanistic position and the main directions of its formation, a complete understanding of its principles and functions have not yet been formulated (Wilde 2004). In the scientific literature, the concept of a humanistic position has a different meaning, and therefore its essence is determined quite differently, which necessitates further research in this direction (PourAli et al. 2017). In most cases, the term is used in the scientific literature to emphasize that it is not enough to talk about the knowledge, skills and abilities necessary for a humanistic position (Peters and Rivas 2018), but it is important to understand how a person interacts with this knowledge as new knowledge can influence the structure and inner world of the individual, how the values of the past are preserved in these new knowledge and constitute the basis for the present (Veugelers 2011).

All approaches to understanding the content of a humanistic position and all of them in combination and interaction point not just at possible way to comprehend the essence of a humanistic position (Brown 1996), but also at the need to form (by human and society) a modern vision of the essence of the phenomenon of a humanistic position (Schwarz 1995). The importance of the development by students of a humanistic position through appropriate innovative activity and way of thinking is rather evident (Letkowitz 2012), because it is precisely the force for evolutionary processes in the sociocultural sphere both currently and in the future (Dierksmeier 2016).

\section{MATERIAL AND METHODS}

Assessment of pedagogical effectiveness by teachers of higher education institutions was performed by means of an expert survey. Diagnostics and processing of empirical data was performed according to the methodology for assessing the importance of each individual requirement for the proposed teaching materials, namely:

1. Functionality: integrative functional and branch orientation of the general cultural and professional training of specialists and the formation of their modern moral and ethical qualities.

2. Worthiness: focus on the formation of a positive motivational and value-based attitude to the acquisition of new knowledge as a means of preparation for future professional activity, further professional becoming and self-determination.

3. Fundamentalization: the appropriateness of introducing the proposed content in the educational process in order to increase the level of professional training of future specialists on the basis of the modern synergetic paradigm of fundamentality.

4. Learning capability: the potential opportunities of the proposed didactic materials for organizing productive educational and cognitive activities in accordance with the principle of the unity of the substantive, procedural and motivational and value-based aspects of training.

Assessment of the pedagogical effectiveness of each of these requirements was performed by experts on a 100point scale; sources of argumentation of the issue - on a 3-point scale (high, medium, low); degree of familiarity with the issue - on a 10-point scale. In order to quantify the significance of each of the implemented requirements, the following indicators are introduced: indicator of generalized thought (M); indicators of the degree of agreement of expert opinions (variation coefficient $-V_{j}$ ) and its statistical significance (according to the Pearson criterion $\left.\mathrm{X}^{2}\right)$; indicators of activity $\left(\mathrm{K}_{\mathrm{a}}\right)$ and competency $\left(\mathrm{K}_{\kappa}\right)$ of experts.

The indicator of the expert's generalized opinion regarding each of the requirements for academic materials that we identified was calculated through the arithmetic mean of the assessment of a specific requirement. The arithmetic mean $\mathrm{M}_{\mathrm{j}}$ of the assessment of a specific requirement (in points), determined by the formula: 


$$
M_{j}=\frac{1}{N_{j}} \sum_{i=1}^{N} C_{i j}
$$

where $j$ is the serial number of the requirement; $i$ is the serial number of the expert; $N$ is the number of experts participating in the assessment (and equals $1,2,3, \ldots \mathrm{N}$ ); $\mathrm{N}_{\mathrm{j}}$ is the number of experts evaluating the $\mathrm{j}^{\text {th }}$ requirement; $\mathrm{C}_{\mathrm{ij}}$ is the assessment of relative importance, put forth by the $\mathrm{i}^{\text {th }}$ expert of the $\mathrm{o}^{\text {th }}$ requirement.

The frequency of the most important estimates (100 points) obtained by the $j^{\text {th }}$ requirement is determined according to the formula:

$$
K_{j}^{l}=\frac{N_{j}^{l}}{N_{j}}
$$

where $N_{j}^{l}$ is the number of maximum possible ratings corresponding to 100 points; ${ }^{\prime}{ }_{j}$ - is the total number of ratings on $\mathrm{j}^{\text {th }}$ requirement.

The sum of the ranks $S_{j}$ obtained by the $j^{\text {th }}$ requirement is defined as:

- $\quad$ ranking was performed to reduce the ratings put forward by experts for each requirement;

- the sum of ranks $S_{j}$ determined by the experts on the $j^{\text {th }}$ requirement was determined according to the following formula:

$$
S_{j}=\sum_{i=1}^{N} R_{i j}
$$

where $R_{i j}$ is the rank of the $i^{\text {th }}$ expert's assessment of the $j^{\text {th }}$ requirement.

The coefficient of variation $V_{j}$ of the estimates obtained by the $j^{\text {th }}$ requirement was determined as follows: the variance of the estimates $D_{j}$ provided by the $j^{\text {th }}$ requirement was determined, factoring in the formula:

$$
D_{j}=\frac{1}{N_{j}-1} \sum_{i=1}^{N}\left(C_{i j}-M_{i j}\right)^{2}
$$

root-mean-square deviation of estimates $\sigma_{j}$ obtained by the $j^{\text {th }}$ requirement was determined by the formula:

$$
\sigma_{j}=\sqrt{D_{j}}
$$

the variation coefficient was determined by requirement:

$$
V_{j}=\frac{\sigma_{j}}{M_{j}}
$$

\section{RESULTS AND DISCUSSION}

As at the stage of the ascertaining experiment, we performed the diagnostics of the level of formation of the humanistic position of students, achieved by them in the process of experimental training, according to the results of diagnostics of the main (partial) components of the humanistic position. With that, we shall use the diagnostic results of the maturity level of certain components of the humanistic position of students at the ascertaining stage of the research as an indicator of the initial control section at the educational stage of the pedagogical experiment. We shall consider these results in more detail. The diagnostic results of the maturity level of the motivational component of the students' humanistic position, at the beginning of an educational experiment, in the control and experimental groups (initial control section) are presented in Fig. 1. 


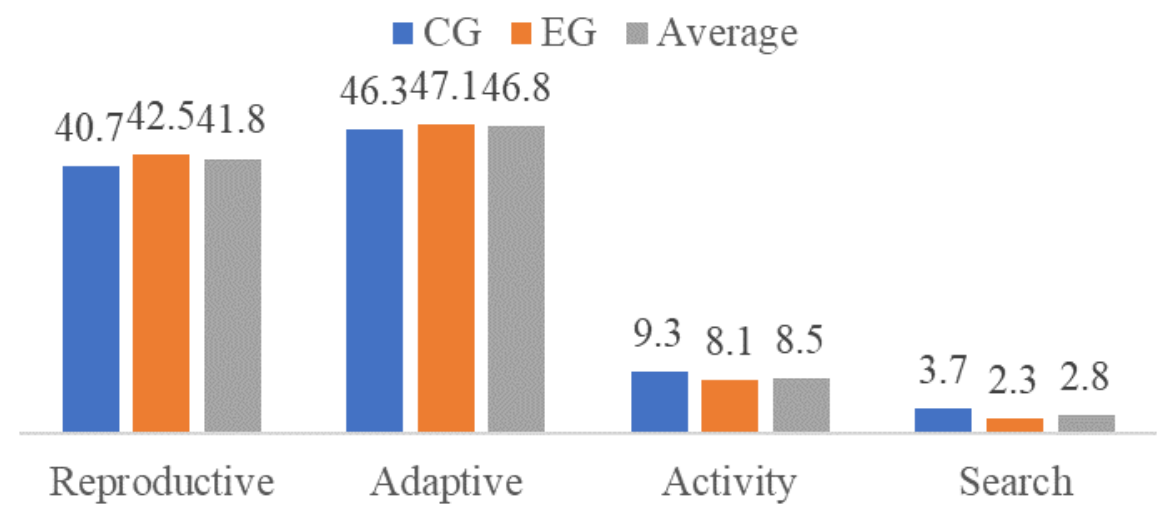

Figure 1. Frequencies of students' distribution according to the levels of formation of the motivational component of the humanistic position

An analysis of the results of the research indicates that only a small number of students has a search level for the maturity of the motivational component of the humanistic position (2.8\% on average). As the analysis of answers $(88.6 \%)$ to certain survey questions indicates, most students have reproductive and adaptive levels of maturity of the motivational component of the humanistic position. They have no need to develop and implement humanistic knowledge ( $88 \%$ of students), are not ready to conduct their own humanistic activity, to evaluate its results (89\% of students). About $94 \%$ of students in the control and experimental groups are not aware of the innovations in humanistic activity, which are part of the humanistic position. Over $83 \%$ of students have never been engaged in the search for theoretical and practical material of innovative processes in culture.

We should also note the low level of students' development of motives for self-improvement and professional self-development (only $23 \%$ of students are ready to discuss with teachers the issues concerning humanization of society). Only $6 \%$ of students said that they enjoy an in-depth study of humanistic knowledge. In most cases, students show either an indifferent attitude, or episodic interest in relation to their own professional activities, including humanistic. An insignificant part of students, as the research indicated, studies various issues of humanistic activity during extracurricular time (attending conferences, participating in social and cultural events, etc.). The results of the diagnosis of the levels of formation of the cognitive component of the students' humanistic position prior to conducting an educational experiment (initial section) are presented in Fig. 2.

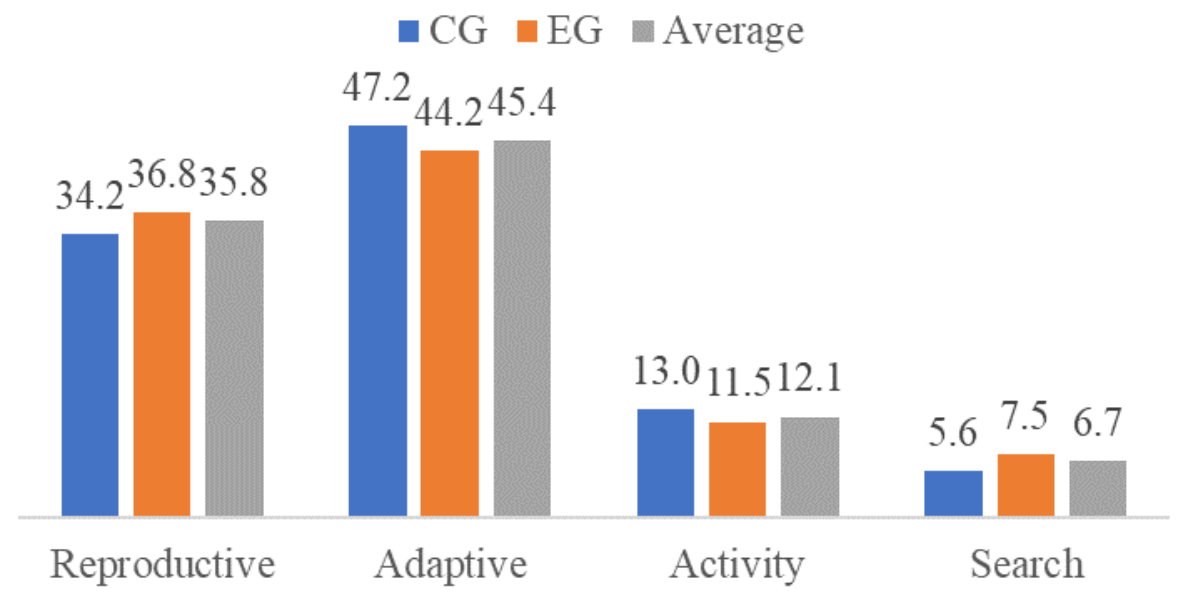

Figure 2. Frequencies of students' distribution according to the maturity level of the cognitive component of the humanistic position.

A comparative analysis of the data displays that the maturity level of the cognitive component of the humanistic position in students of both the experimental and control groups is slightly higher than the motivational component. This is due to the fact that 4th year students have already mastered certain aspects of humanistic activity. In $18.8 \%$ of students, activity and search maturity levels of the cognitive component of the humanistic 
position were revealed, and $81.2 \%$ of students remain at the reproductive and adaptive levels.

In the course of the diagnostic research, we discovered that students encountered great difficulties in answering questions concerning the nature and structure of the humanistic position, the innovative potential of humanistic activity, and the specifics of humanistic work in the field of culture. The diagnostic results of the maturity levels of the reflective component of the students' humanistic position prior to conducting an educational experiment (initial control section) are presented in Fig. 3.

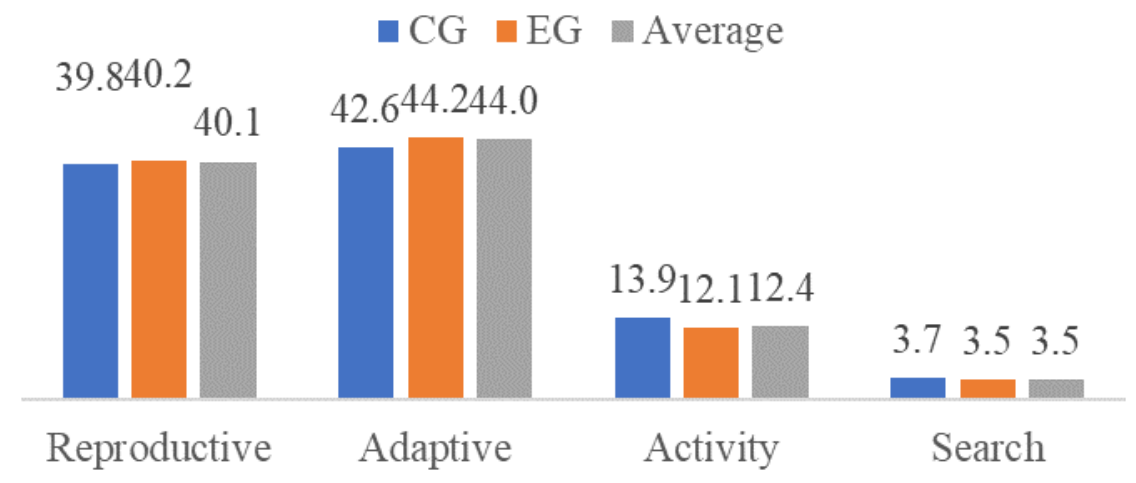

Figure 3. The frequency of students' distribution according to the maturity level of the reflective component of the humanistic position

The research results presented in Fig. 3 indicate that only $15.9 \%$ of students reached the active and search maturity levels of the reflexive component of the humanistic position in most students, elementary and reproductive levels were determined. It is noteworthy that more than $40 \%$ of students evaluate their ability for self-reflection only at the reproductive level. This suggests that students in both the experimental and control groups have either an inflated or low self-esteem of the development of professionally important knowledge and skills, as well as the qualities necessary for their own humanistic activities. An analysis of the diagnostics results of the maturity level of the emotional component of the humanistic position of students prior to conducting an educational experiment (initial section) is presented in Fig. 4.

\section{- $\mathrm{CG}$ EG $\approx$ Average}

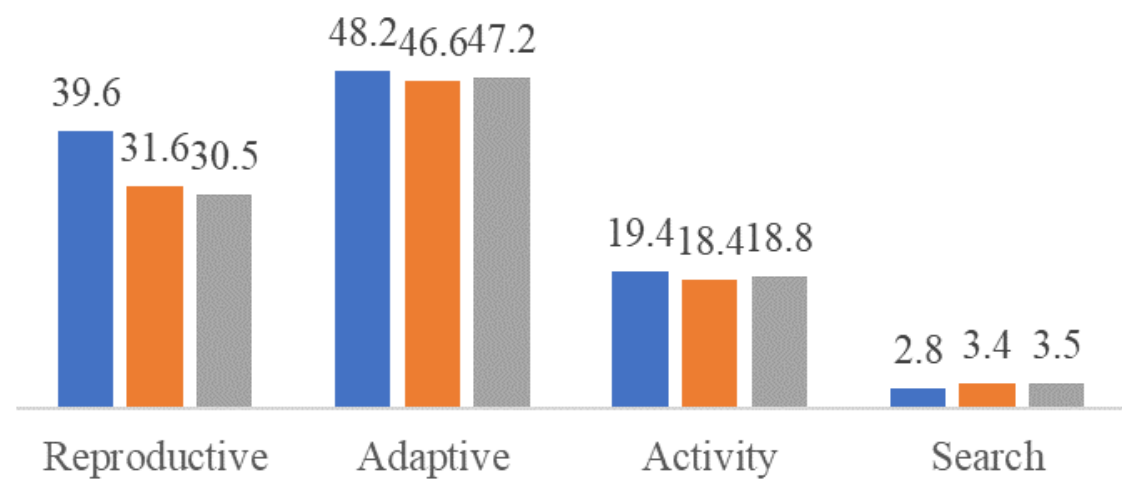

Figure 4. Frequencies of students' distribution according to the maturity levels of the emotional component of the humanistic position

We shall analyse the obtained results. One third of students in both the experimental and control groups experience negative emotional states with regard to humanization; humanistic activity is foremost associated 
with anxiety. More than $40 \%$ of students are indifferent to humanization; their use conjures a state close to irritation. And only a fifth of students of both groups experience positive emotional states regarding humanization, determine the positive motivation for learning, and cause them to experience interest, curiosity and enjoyment. The diagnostic results of the maturity levels of the gnostic component of the humanistic position of students prior to conducting an educational experiment (initial section) are presented in Fig. 5.

-CG $\backsim \mathrm{EG} \approx$ Average

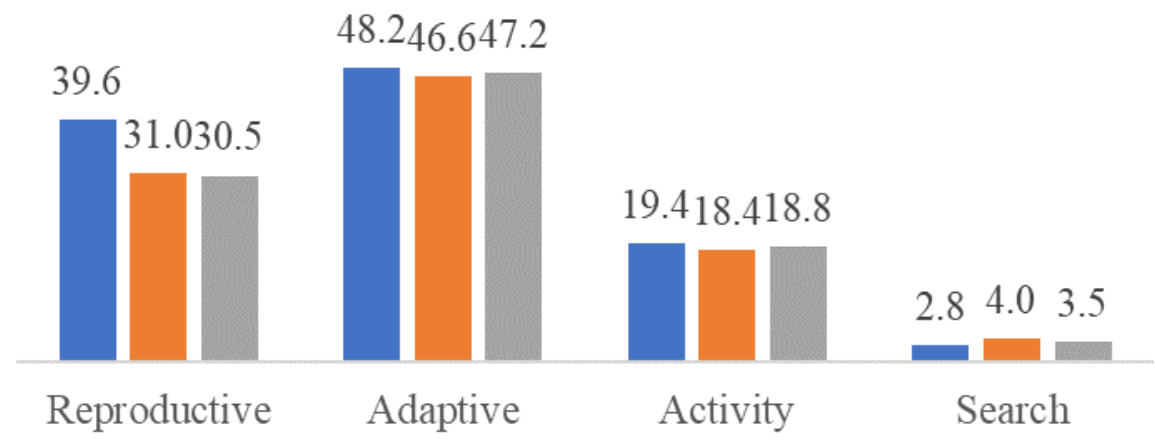

Figure 5. Frequencies of students' distribution according to the maturity levels of the gnostic component of the humanistic position

The research results presented in Fig. 5 indicate that only $22.3 \%$ of students are at the activity and search maturity levels of the gnostic component of the humanistic position, most students $(77.7 \%)$ have reproductive and adaptive levels. This suggests that students of both the experimental and control groups have an insignificant level of cognitive and analytical abilities of humanistic activity. They are responsible for the research of theoretical issues of humanistic activity, but are not sure that it is important for them in further professional and practical activities, their humanistic culture is very superficial. Students insufficiently understand the role and importance of humanistic activity, have sufficient knowledge to solve some professional and practical issues, differentially implement a critical analysis of their personal humanistic activity and personal culture, but don't understand the goals and objectives of future professional activity, humanistic direction, having a "polar" professional self-esteem. Such a student is characterized by observation, ingenuity, creativity. They partially possess the ability to justify, analyse, systematize and generalize experience, see contradictions and issues. They are capable of searching, but are not ready to evaluate the effectiveness; capable of development and implementation in the field of cultural and creative activities.

The diagnostic results of the maturity levels of the activity component of the students' humanistic position before conducting an educational experiment (initial section) are presented in Fig. 6. As a result of the qualitative and quantitative analysis of the diagnostic results, we came to the conclusion that $80 \%$ of students indicated a reproductive and adaptive maturity level of the active component of the humanistic position, that is, students who are incapable of searching and evaluating, developing and implementing, but in some cases $(32 \%)$ are ready to evaluate the effectiveness. 


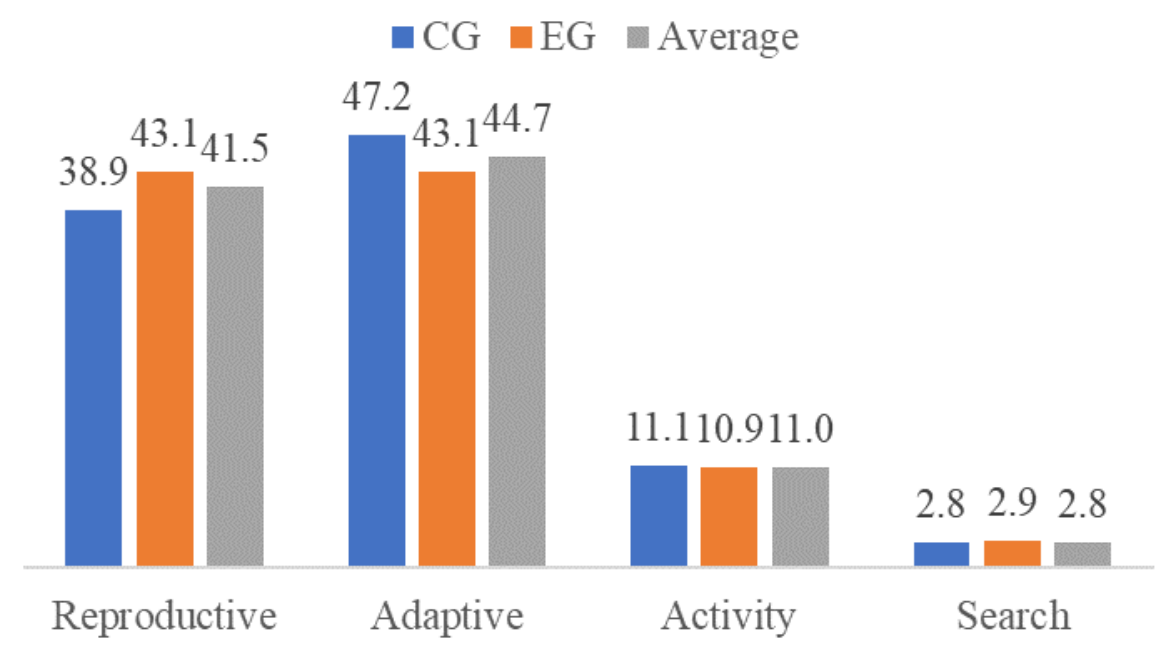

Figure 6. Frequencies of students' distribution according to the maturity level of the activity component of the humanistic position

Only $13.8 \%$ of students reached activity and search maturity levels of a humanistic position. This indicator is the lowest among all other components of the humanistic position, which is not surprising, as no discipline of the curriculum for preparing students refers to the formation of ideas concerning the content and role of humanization in public life. This confirms the hypothesis of our research on the need to implement the selected organizational and pedagogical conditions for the formation of a humanistic position.

After the implementation of the organizational and pedagogical conditions for the formation of theoretical and methodological foundations and, in particular, the organizational and pedagogical conditions for the formation of the humanistic position of students, we performed a control diagnostic of all partial components of the humanistic position. A comparative analysis of the diagnostic results of the maturity levels of the motivational component of the students' humanistic position before and after an educational experiment (initial and final sections) is presented in Fig. 7.

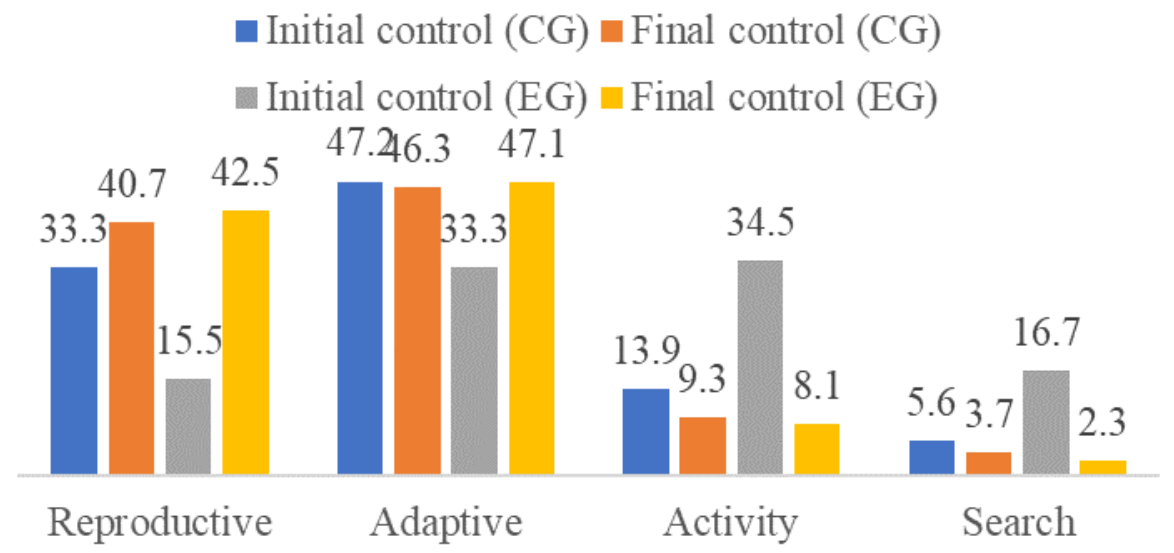

Figure 7. Distribution of students in the control and experimental groups according to the maturity level of the motivational component of the humanistic position

Fig. 7 data indicate that the number of students in the experimental group with an active and search maturity level of the motivational component of the students' humanistic position has significantly increased. In the control group, no significant changes occurred. After the educational experiment, students of the experimental group underwent significant changes in the hierarchy of motives of professional activity: motives of professional self- 
development began to emerge and dominate, interest in the development and implementation of technologies and programs in the practices in the field of culture. Students displayed interest in periodicals on various issues of humanistic activity. Almost $64 \%$ of students in the experimental group (versus $14 \%$ of students in the control group) are ready to discuss the issues of humanistic professional activity with teachers and analyse various issues of introducing innovations in various cultural areas. Most students of the experimental group expressed a willingness to perform independent humanistic activities (68\%.). The indifferent attitude and episodic interest in humanistic activity among students of the experimental group changed to curiosity and professional interest. Comparative diagnostic results of the maturity levels of the cognitive component of the students' humanistic position before and after the educational experiment (initial and final sections) are presented in Fig. 8.

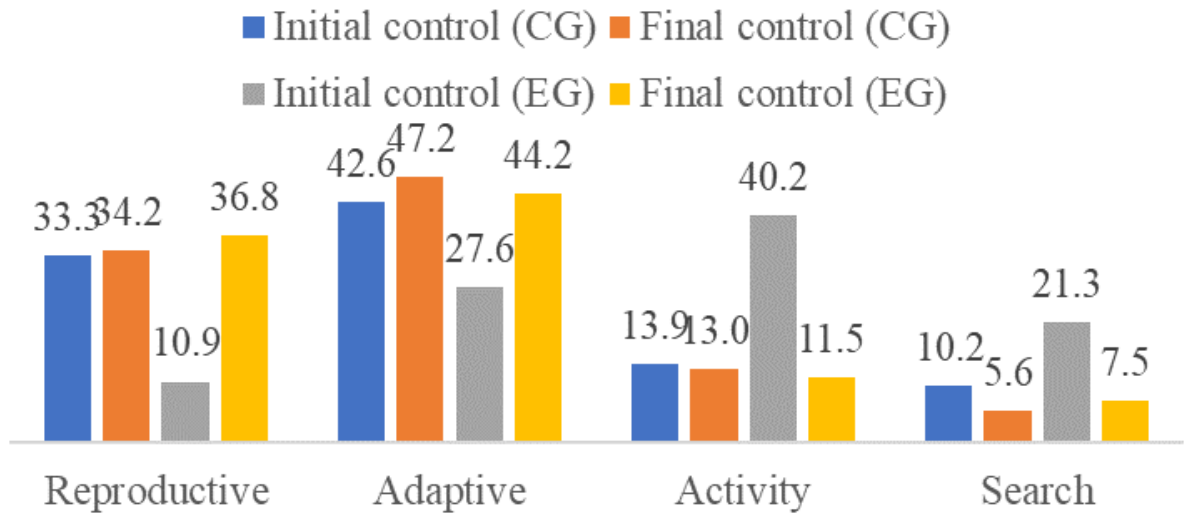

Figure 8. Frequency of distribution of students in the control and experimental groups according to the maturity level of the cognitive component

The data in Figure 8 indicate that the number of students in the experimental group with activity and search maturity levels of cognitive component increased. A significant part of the students of the experimental group $(64 \%)$ managed to complete the test tasks. Students managed to correctly describe the phases and stages of the innovation process, highlighted all the structural components of the innovation process; listed all the factors that contribute to the emergence of innovations in humanistic activity. In the control group, there were no such significant shifts.

In our opinion, it is precisely the conduct of focused work within the framework of the educational experiment, as well as the introduction of the discipline "Culture and Science" into the educational process, that led students to significantly expand and deepen their knowledge in the field of humanistic activities, technologies and programs. Comparative diagnostic results of the maturity levels of the reflective component of the humanistic position of students before and after the educational experiment (initial and final sections) are presented in Fig. 9.

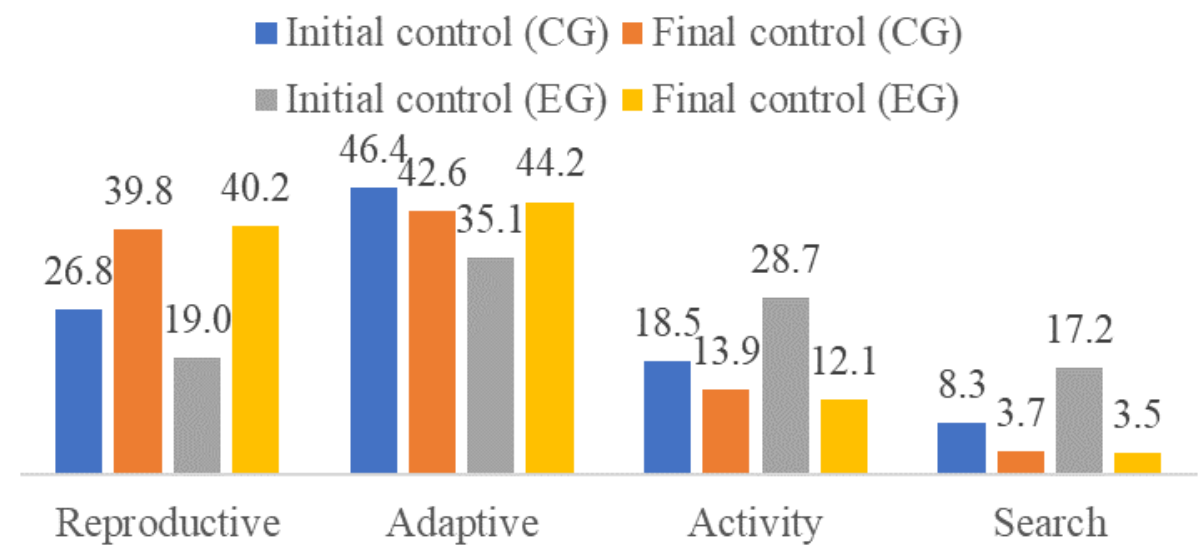

Figure 9. The distribution frequencies of students in the control and experimental groups according to the maturity levels of the reflective component of the humanistic position 
As is evident, there are noticeable changes in the maturity levels of the reflective component of the humanistic position of students of the experimental group. In students of the control group, changes are less noticeable. After the educational experiment, students of the experimental group started evaluating themselves more adequately, but could not always evaluate the real level of their humanistic position. Comparative diagnostic results of the maturity levels of the emotional component of the students' humanistic position before and after the educational experiment (initial and final sections) are presented in Fig. 10.

\section{- Initial control (CG) $₫$ Final control (CG) \\ - Initial control (EG) $\square$ Final control (EG)}

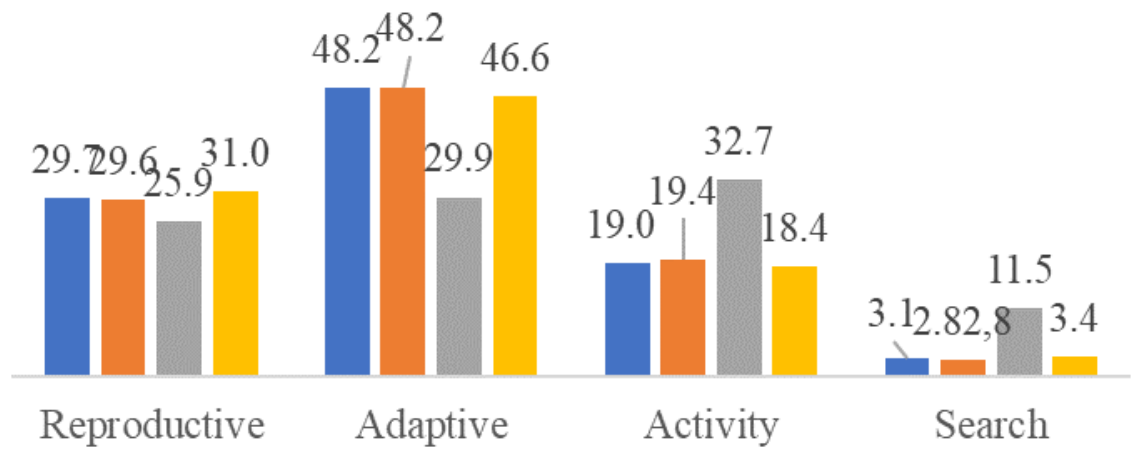

Figure 10. Frequencies of distribution of students in the control and experimental groups according to the maturity levels of the emotional component

Fig. 10 data suggests that in the experimental group the number of students with search and activity maturity levels of formation of the emotional component of the humanistic position has significantly increased. Students of the experimental group had their level of professional anxiety decreased. A significant part of the students of the experimental group experiences a variety of emotional states with regard to humanism, from anxiety to a feeling of curiosity, its use is of interest to them. Comparative diagnostic results of the maturity levels of the gnostic component of the humanistic position of students before and after the educational experiment (initial and final sections) are presented in Fig. 11.

\section{- Initial control (CG) $\approx$ Final control (CG) \\ « Initial control $(\mathrm{EG}) \backsim$ Final control $(\mathrm{EG})$}

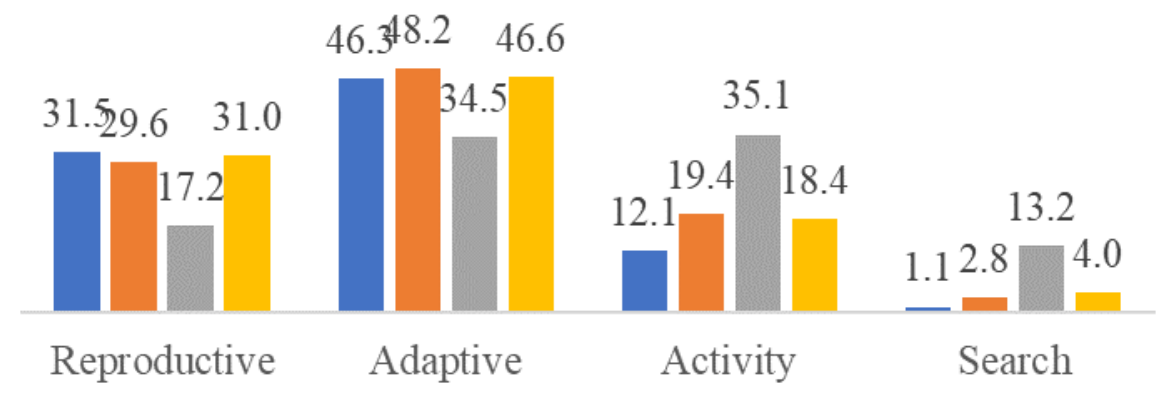

Figure 11. Frequency of distribution of students in the control and experimental groups according to the maturity levels of the gnostic component 
Fig. 11 data suggests that in the experimental group the number of students with search and active maturity levels of the gnostic component of the humanistic position significantly increased. Students of the experimental group improved their observation, acumen, and the ability to analyse, justify, systematize, and generalize the material. A significant part of the students of the experimental group became more open to creativity, to gumption. Comparative diagnostic results of the maturity levels of the activity component of the humanistic position of students before and after the educational experiment are presented in Fig. 12.

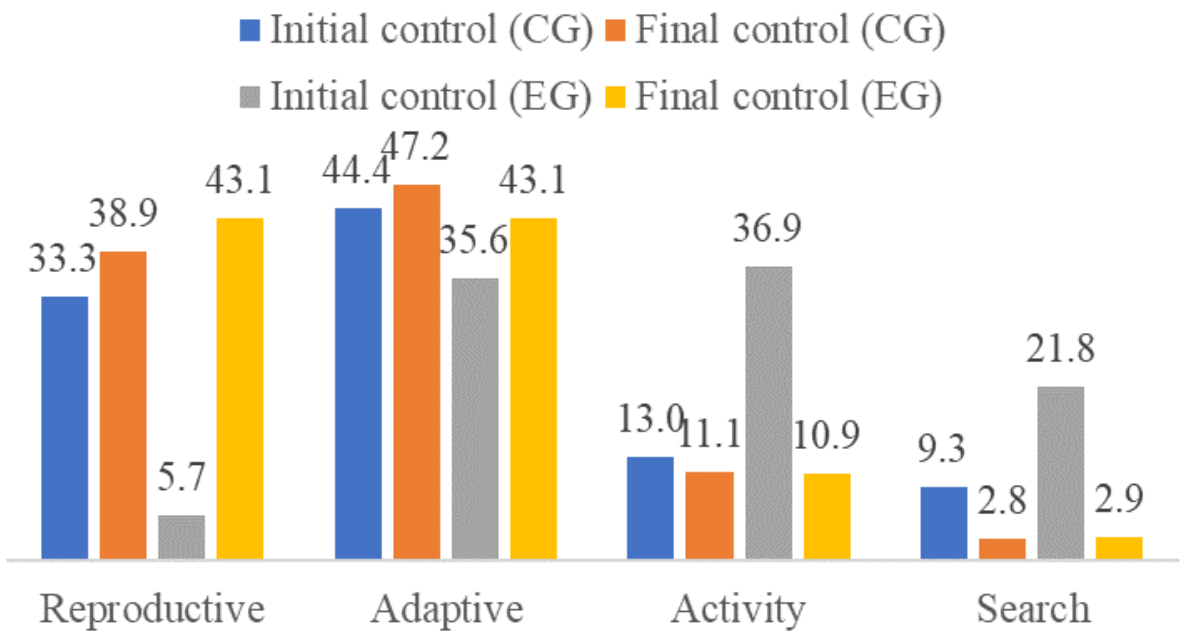

Figure 12. Frequency of distribution of students in the control and experimental groups according to the maturity level of the activity component

The analysis of the results indicates that there are significant changes in the maturity levels of the activity component of the humanistic position among students of the experimental group. A significant part of students displayed the ability to search and evaluate, including foreign forms of humanism, the ability to develop and implement humanistic technologies in future professional activities. Students in the control group also had their indicators changed, but not as significantly, sometimes only nominally. We associate such an increase in the maturity level of the humanistic position with the conduct of the educational experiment aimed at systematization and generalization of knowledge and skills, the development of professionally important qualities and personality traits of a future specialist that determine the success of their professional activity in the humanistic environment of cultural institutions, a stable system of motives for development, a comprehensive introduction and development of new modern innovative technologies and programs, as well as the psychological attitude towards performance of transformative action and competence of their implementation in the course of humanistic activities. We shall consider the summary results of the analysis of the data of the initial and final sections of the educational experiment (Table 1).

Table 1. Summary data on the dynamics of the distribution frequencies of students in the EG and CG by the maturity levels of the humanistic position at the stages of the initial and final sections of the educational experiment

\begin{tabular}{|c|c|c|c|c|c|c|c|c|c|}
\hline \multirow{4}{*}{ Components } & \multirow{4}{*}{ Control } & \multicolumn{8}{|c|}{ Number of students, $\%$} \\
\hline & & \multirow{2}{*}{\multicolumn{8}{|c|}{$\begin{array}{l}\text { EG } \\
\text { Maturity levels }\end{array}$}} \\
\hline & & & & & & & & & \\
\hline & & Reproductive & Adaptive & Activity & Search & Reproductive & Adaptive & Activity & Search \\
\hline \multirow{2}{*}{ Motivational } & $\begin{array}{l}\text { Initial } \\
\text { control }\end{array}$ & 15.5 & 33.3 & 34.5 & 16.7 & 33.3 & 47.2 & 13.9 & 5.6 \\
\hline & $\begin{array}{l}\text { Final } \\
\text { control }\end{array}$ & 42.5 & 47.1 & 8.1 & 2.3 & 40.7 & 46.3 & 9.3 & 3.7 \\
\hline \multirow[t]{2}{*}{ Cognitive } & $\begin{array}{l}\text { Initial } \\
\text { control }\end{array}$ & 10.9 & 27.6 & 40.2 & 21.3 & 33.3 & 42.6 & 13.9 & 10.2 \\
\hline & Final & 36.8 & 44.2 & 11.5 & 7.5 & 34.2 & 47.2 & 13 & 5.6 \\
\hline
\end{tabular}




\begin{tabular}{|c|c|c|c|c|c|c|c|c|c|}
\hline & control & & & & & & & & \\
\hline \multirow{2}{*}{ Reflexive } & $\begin{array}{l}\text { Initial } \\
\text { control }\end{array}$ & 19 & 35.1 & 28.7 & 17.2 & 26.8 & 46.4 & 18.5 & 8.3 \\
\hline & $\begin{array}{l}\text { Final } \\
\text { control }\end{array}$ & 40.2 & 44.2 & 12.1 & 3.5 & 39.8 & 42.6 & 13.9 & 3.7 \\
\hline \multirow{2}{*}{ Emotional } & $\begin{array}{l}\text { Initial } \\
\text { control }\end{array}$ & 25.9 & 29.9 & 32.7 & 11.5 & 29.7 & 48.2 & 19 & 3.1 \\
\hline & $\begin{array}{l}\text { Final } \\
\text { control }\end{array}$ & 31 & 46.6 & 18.4 & 3.4 & 29.6 & 48.2 & 19.4 & 2.8 \\
\hline \multirow{2}{*}{ Activity } & $\begin{array}{l}\text { Initial } \\
\text { control }\end{array}$ & 5.7 & 35.6 & 36.9 & 21.8 & 33.3 & 44.4 & 13 & 9.3 \\
\hline & $\begin{array}{l}\text { Final } \\
\text { control }\end{array}$ & 43.1 & 43.1 & 10.9 & 2.9 & 38.9 & 47.2 & 11.1 & 2.8 \\
\hline \multirow{2}{*}{ Gnostic } & $\begin{array}{l}\text { Initial } \\
\text { control }\end{array}$ & 17.2 & 34.5 & 35.1 & 13.2 & 31.5 & 46.3 & 12.1 & 1.1 \\
\hline & $\begin{array}{l}\text { Final } \\
\text { control }\end{array}$ & 31 & 46.6 & 18.4 & 4 & 29.6 & 48.2 & 19.4 & 2.8 \\
\hline \multirow{2}{*}{$\begin{array}{l}\text { Average } \\
\text { value }\end{array}$} & $\begin{array}{l}\text { Initial } \\
\text { control }\end{array}$ & 15.70 & 32.67 & 34.68 & 16.95 & 31.32 & 45.85 & 15.07 & 6.27 \\
\hline & $\begin{array}{l}\text { Final } \\
\text { control }\end{array}$ & 37.43 & 45.30 & 13.23 & 3.93 & 35.47 & 46.62 & 14.35 & 3.57 \\
\hline \multirow{2}{*}{ Dispersion } & $\begin{array}{l}\text { Initial } \\
\text { control }\end{array}$ & \multicolumn{4}{|l|}{0.902} & \multicolumn{4}{|l|}{0.714} \\
\hline & $\begin{array}{l}\text { Final } \\
\text { control }\end{array}$ & \multicolumn{4}{|l|}{0.637} & \multicolumn{4}{|l|}{0.621} \\
\hline $\begin{array}{l}\text { Pearson's t- } \\
\text { criterion }\end{array}$ & & \multicolumn{2}{|l|}{$t_{E P-E K}=6.783$} & \multicolumn{2}{|c|}{$t_{\text {EK-Кк }}=0.28$} & \multicolumn{2}{|l|}{$\mathrm{t}_{\mathrm{KP}-\mathrm{KK}}=0.785$} & \multicolumn{2}{|c|}{$\mathrm{t}_{\mathrm{EP}-\mathrm{K} \Pi=5.758}$} \\
\hline Conclusions & & \multicolumn{2}{|c|}{ Changes are significant } & \multicolumn{2}{|c|}{$\begin{array}{l}\text { Changes are } \\
\text { insignificant }\end{array}$} & \multicolumn{2}{|c|}{ Changes are insignificant } & \multicolumn{2}{|c|}{$\begin{array}{l}\text { Changes } \\
\text { significant }\end{array}$} \\
\hline
\end{tabular}

The presented data indicate that the number of students who reached activity and search maturity levels of the humanistic position in the experimental group increased significantly from $17.2 \%(13.23 \%+3.93 \%=17.16 \%$ $\approx 17.2 \%)$ to $51.5 \%$; at the same time, the number of such students in the control group is much smaller $(34.68 \%$ $+16.95 \%=51.53 \% \approx 51.5 \%$ ). In order to justify the statistical reliability of the results of experimental research work, we applied the K. Pearson's criterion of significance. The findings are as follows:

- at the beginning of the experiment tЕК-КK $=0.28<2.576$ - the differences between the EG and the CG according to the data of the ascertaining section are insignificant;

- after conducting the educational experiment for CG tKP-KK $=0.785<2.576$, - changes in the CG are also insignificant;

- $\quad$ after completion of the educational experiment for $E G t_{E P-E K}=6.78>2.576$, - the changes are significant;

- according to the data of the final section after the experiment, tEP-KP $=5.758>2.576,-$ that is, changes in the EG compared to the CG are also significant.

Therefore, the value of the Pearson criterion confirms the reliability of a significant increase in the number of students of the experimental group with active and search maturity levels of the humanistic position. Significant changes in the values of maturity indicators of the humanistic position and its components in students of the control group were not identified. This allows us to admit that the discovered differences in the experimental and control groups cannot be explained by random reasons, but are the result of a targeted impact, that is, the consequences of the implementation of the theoretical foundations of the formation of students' humanistic position in the process of experimental training.

The results of observations and interviews with students suggest that in the experimental group the maturity level of the students' humanistic position in all indicators significantly increased. Students became interested and responsible in their attitude towards humanistic activity. In the system of motivational sphere there are motives of creative activity, although they not sustainable with all students. Students of the experimental group started actively participating in the development and implementation of innovative projects (and especially in the process of performing individual tasks). Students of the experimental group began to better understand the role and importance of innovation in future professional practice; have sufficient knowledge to solve practically oriented professional tasks; are capable of critical analysis of their personal humanistic activities; professional 
self-esteem is more adequate; they experience various emotional states in relation to humanism, ranging from anxiety to sensations of curiosity; are capable of searching and evaluating and showing readiness for their use in future professional activities.

All of the above confirms the sufficiently high pedagogical effectiveness of experimental training. And this means that the introduction of the theoretical and methodological foundations of the formation of the humanistic position of students in the educational process of a higher educational institution positively affected the effectiveness of their professional training.

\section{CONCLUSIONS}

In accordance with the developed methodology for conducting a research on the formation of the humanistic position of students in a higher educational institution, the maturity level of the indicated qualities of future specialists with an orientation to the selected criteria was tested, forms and methods for managing educational and cognitive activities were worked out, corrections were made and relevant practical recommendations were developed. Our respondents were teachers and university students, facilitating the comprehensive analysis of the researched problematics of professional training of future specialists. Pedagogical observations of the educational activities of students of higher pedagogical educational institutions of culture, conversations, interviewing students and teachers allowed to identify conditions for improving the professional training of students, which in turn facilitated the selection and verification of rational forms and methods of this work, the test of the "Culture and Science" course and its educational and methodological content, the determination of the level of educational achievements of students. The logic of the procedures of the ascertaining stage of the experiment was built in the search for the theoretical basis of the research, the study of the practical experience of higher education institutions, in terms of analysing the content of existing curricula and training programs for students, developing criteria, indicators and performing diagnostics of the maturity level of the humanistic position of students.

The identified gaps in the formation of the humanistic position of students in the educational process of higher education institutions had to be addressed at the educational stage of the pedagogical experiment. In accordance with the developed experimental work program, the analysis of the effectiveness of the developed theoretical and methodological foundations on the dynamics of the formation of the students' humanistic position and the development of relevant recommendations on the formation of the indicated quality of future specialists at the university was performed. To directly perceive the behaviour of the subject of research in various situations, we applied the observation method.

Statistical processing of the research results indicated that during the experiment, the dependence of the maturity levels of the students' humanistic position on the updating of the educational process of training specialists on the basis of the developed theoretical and methodological foundations is expressly evident: providing students with opportunities for real humanistic activity during their professional training at the university; formation of innovative experience and a corresponding way of thinking, conditioned by the content and characteristics of future professional activities in the field of humanistic practice; fulfilment and increase of creative potential, value-based attitude to the creation and implementation of novelties; formation of readiness for learning and personal self-improvement throughout life; impacts on the motivational and value-based sphere of the individual in relation to future professional practice; focus of the educational process on improving the general culture of the personality of students; formation of their skills of critical assessment and forecasting of the social consequences of humanistic activity.

\section{REFERENCES}

1. Aloni N. 2003a. Between the classical and post-modern: milestones and central approaches in humanistic education. In: Enhancing Humanity: The Philosophical Foundations of Humanistic Education (pp. 9-59). Dordrecht: Springer Netherlands. https://doi.org/10.1007/978-1-4020-6168-4_1

2. Aloni N. 2003b. Education towards humanistic morality in an era of value crisis. In: Enhancing Humanity: The Philosophical Foundations of Humanistic Education (pp. 119-171). Dordrecht: Springer Netherlands. https://doi.org/10.1007/978-1-4020-6168-4_3

3. Aloni N. 2003c. Humanistic education in the test of current events. In: Enhancing Humanity: The Philosophical Foundations of Humanistic Education (pp. 173-214). Dordrecht: Springer Netherlands. https://doi.org/10.1007/978-1-4020-6168-4_4 
4. Bakker, D. 2011. Humanistic teaching in practice. In: W. Veugelers (Ed.), Education and Humanism: Linking Autonomy and Humanity (pp. 145-161). Rotterdam: SensePublishers. https://doi.org/10.1007/978-94-6091577-2_11

5. Brown, S.I. 1996. Towards humanistic mathematics education. In: A.J. Bishop, K. Clements, C. Keitel, J. Kilpatrick, \& C. Laborde (Eds.), International Handbook of Mathematics Education: Part 1 (pp. 1289-1321). Dordrecht: Springer Netherlands. https://doi.org/10.1007/978-94-009-1465-0_37

6. Dierksmeier, C. 2016. Toward a humanistic paradigm? In: Reframing Economic Ethics: The Philosophical Foundations of Humanistic Management (pp. 103-120). Cham: Springer International Publishing. https://doi.org/10.1007/978-3-319-32300-8_5

7. Fabian, B., and Vierhaus, R. 1979. The calling and condition of the humanistic disciplines. Minerva, 17(4), 549-554. https://doi.org/10.1007/BF01101903

8. Gregersen, F., and Køppe, S. 1989. A normative theory of humanistic knowledge. Zeitschrift Für Allgemeine Wissenschaftstheorie, 20(1), 40-53. https://doi.org/10.1007/BF01801401

9. Kato, M. 2014. Significance of the rhetorical and humanistic tradition for education today. Asia Pacific Education Review, 15(1), 55-63. https://doi.org/10.1007/s12564-013-9297-2

10. Kwak, D.-J. 2017. A role of doing philosophy in a humanistic approach to teacher education. In: M.A. Peters, B. Cowie, \& I. Menter (Eds.), A Companion to Research in Teacher Education (pp. 69-86). Singapore: Springer Singapore. https://doi.org/10.1007/978-981-10-4075-7_5

11. Letkowitz, J. 2012. From humanitarian to humanistic work psychology: the morality of business. In: S.C. Carr, M. MacLachlan, \& A. Furnham (Eds.), Humanitarian Work Psychology (pp. 103-125). London: Palgrave Macmillan UK. https://doi.org/10.1057/9781137015228_5

12. Parkinson, G.H.R. (1987). Humanistic education: some philosophical considerations. In: R. Straughan \& J. Wilson (Eds.), Philosophers on Education (pp. 93-106). London: Palgrave Macmillan UK. https://doi.org/10.1007/978-1-349-08106-6_7

13. Peters, H.C., and Rivas, M. 2018. The self-model of humanistic supervision. International Journal for the Advancement of Counselling, 40(3), 237-254. https://doi.org/10.1007/s10447-018-9323-5

14. PourAli, P., SeifNaraghi, M., and Naderi, E. 2017. Humanistic education and students' educational motivation in Tehran primary schools. International Journal of Mental Health and Addiction, 15(2), 312-322. https://doi.org/10.1007/s11469-016-9703-1

15. Schwarz, D.R. 1995. The case for humanistic formalism. In: The Transformation of the English Novel, 1890-1930: Studies in Hardy, Conrad, Joyce, Lawrence, Forster and Woolf (pp. 141-176). London: Palgrave Macmillan UK. https://doi.org/10.1057/9780230379336_8

16. Suransky, C. 2017. Humanistic education for teaching in a globalizing world. In: M. Walker \& M. WilsonStrydom (Eds.), Socially Just Pedagogies, Capabilities and Quality in Higher Education: Global Perspectives (pp. 109-128). London: Palgrave Macmillan UK. https://doi.org/10.1057/978-1-137-55786-5_6

17. Veugelers, W. 2011. A humanist perspective on moral development and citizenship education. In: W. Veugelers (Ed.), Education and Humanism: Linking Autonomy and Humanity (pp. 9-34). Rotterdam: SensePublishers. https://doi.org/10.1007/978-94-6091-577-2_2

18. Weiner, B. 1985. Humanistic theory and personal constructs. In: Human Motivation (pp. 407-436). New York: Springer New York. https://doi.org/10.1007/978-1-4612-5092-0_9

19. Wilde, L. 2004. Humanistic ethics. In: Erich Fromm and the Quest for Solidarity (pp. 37-55). New York: Palgrave Macmillan US. https://doi.org/10.1007/978-1-137-07511-6 3

20. Zilsel, E., Raven, D., Krohn, W., and Cohen, R.S. 2003. The methods of humanism. In: D. Raven, W. Krohn, \& R.S. Cohen (Eds.), The Social Origins of Modern Science (pp. 22-64). Dordrecht: Springer Netherlands. https://doi.org/10.1007/978-94-011-4142-0_3 